\title{
A genetic study of esterase activity in mules, hinnies and their backcross progeny
}

\author{
G. FAN, E. ZONG \& Z. ZHAO \\ Lanzhou Institute of Animal Sciences, Chinese Academy of Agricultural Sciences, Lanzhou, Gansu, People's Republic of \\ China 730050
}

\begin{abstract}
Eight $\mathrm{B}_{1}$ progeny produced by backcrossing fertile female mules and hinnies with donkeys or horses, were assessed for levels of esterase isozyme in their sera. Four bands are found in horses, three fast moving $\left(E_{3}\right)$ and one slow $\left\langle E_{1}\right)$, while donkeys show only the slow $E_{1}$ band. Mules and hinnies, the $F_{1}$ hybrids of the horse and donkey, show both the $E_{1}$ and $E_{3}$ bands. Among the eight tested backcross $\left(B_{1}\right)$ progeny, a variety of different combinations are found, depending on whether or not the horse band $\left(E_{3}\right)$ has been trasmitted by the mule or hinny parent. The significance of this result is because it shows that irregular patterns of segregation of the horse and donkey chromosomes exist between different $F_{1}$ hybrids, contrary to some hypotheses proposed previously.
\end{abstract}

Keywords: esterase, hinny, horse-donkey hybrids, mule.

\section{Introduction}

In 1964, Kaminski \& Gajos reported that four bands of esterase isozyme exist in the horse (Equus caballus) serum, three $\left(E_{3}\right)$ being fast moving on an acrilamide gel, the fourth $\left(\mathrm{E}_{1}\right)$ being slow. In the donkey (E. asinus) only the $E_{1}$ band is found. $F_{1}$ reciprocal hybrids of horses and donkeys, the mule and hinny, both contain $E_{1}$ and $E_{3}$ in their serum. The existence or nonexistence of specific esterase isozyme bands is thus a characteristic species difference between the horse and donkey, and this is considered to be an extremely reliable and objective genetic marker for the study of hybrids between the two species ( $\mathrm{Hu} \&$ Wan, 1985; Zheng, 1987).

Esterase isozyme serum levels were recently tested in two backcross $\left(B_{1}\right)$ progeny from a fertile hinny $\times$ jack donkey cross (Zong \& Fan, 1989). One showed the presence of a fast moving $\mathrm{E}_{3}$ horse band (contributed by the hinny), the other did not. Tests have now been carried out on a further eight $B_{1}$ hybrids, the findings are reported in this paper. Horses, donkeys, mules and hinnies were used as controls.

\section{Materials and methods}

\section{Animals}

A series of strong and healthy animals, all aged between 1.5 and 19 years, with the exception of one aged 0.5 years, were investigated in the study. They included the following.

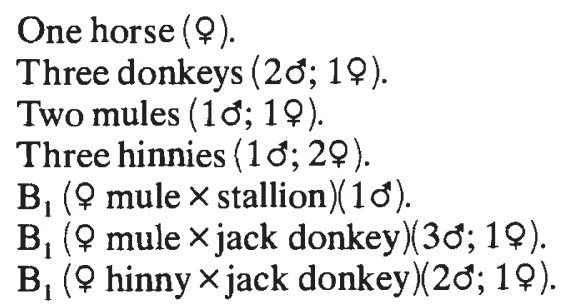

\section{Serum preparation}

Blood was collected by sterile venipuncture from the neck. It was transferred to small bottles and allowed to sediment for 1-3 h, serum then being removed and placed in the freezer $\left(-20^{\circ} \mathrm{C}\right)$. It was kept on ice when being moved.

\section{Esterase isozyme testing}

Three methods were initially applied; thin isoelectrofocusing (IEF), high voltage flat-slab electrophoresis and vertical flat-slab electrophoresis. The results of all three test methods proved the same, so only the IEF method will be described. A $0.5 \mathrm{~mm}$ gel board of polyacrylamide was made. The electrolyte was 40 per cent ampholine of $\mathrm{pH}$ range 3.5-5.5. The voltage used was $1500 \mathrm{~V}$, current $25 \mathrm{~mA}$, power $20 \mathrm{~W}$, time $2 \mathrm{~h}$. The density of sample was 1:20 the volume $30 \mu \mathrm{l}$ and the location was the negative pole. 


\section{Staining}

$\alpha$-Napthyl acetate was mixed with fast blue RR and pre-heated at $37^{\circ} \mathrm{C}$ in a container immersed in water. The gel membrane was placed in the mixture after IEF and brown bands appeared, 7 per cent acetic acid was used for differentation.

\section{Scanning}

The gel membrane was scanned using a Dual Wavelength TLC Scanner-910, the sample wave of which was $610 \mathrm{~nm}$ in length and the reference wave $700 \mathrm{~nm}$.

\section{Results}

Scanning graphs for the horse, donkey, mule and hinny are shown in Fig. 1. The wave peak for the fast band $\left(E_{3}\right)$ ranged from 0.66 to 0.78 and was present in the horse (Fig. 1a), the mule (Fig. 1c), and the hinny (Fig. 1d), this band, in the hybrids, was transmitted from the horse parent. A fast band was not detectable in the donkey (Fig. 1b).

Figure 2 gives the result for the $B_{1}$ male offspring of a female mule and stallion. The $E_{3}$ band is very obvious although there is no means to determine whether it was transmitted by the horse or the mule. Figure $3 a-d$ shows the results for the four $B_{1}$ progeny of females mules and jack donkeys. In spite of them all being produced by the same type of cross, a variation can be seen in the inheritance pattern of esterase isozyme.

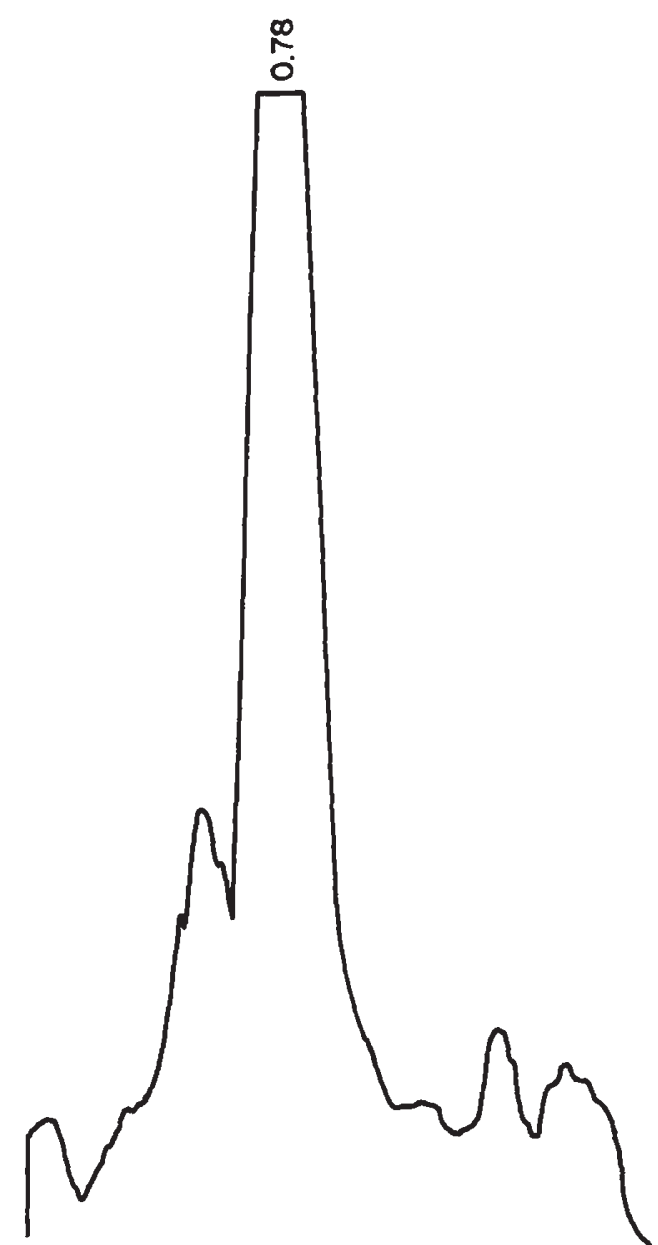

Fig. 2 Scanning graphs showing esterase bands in $\mathrm{B}_{1}$ o ( $\%$ mule $\times$ stallion)
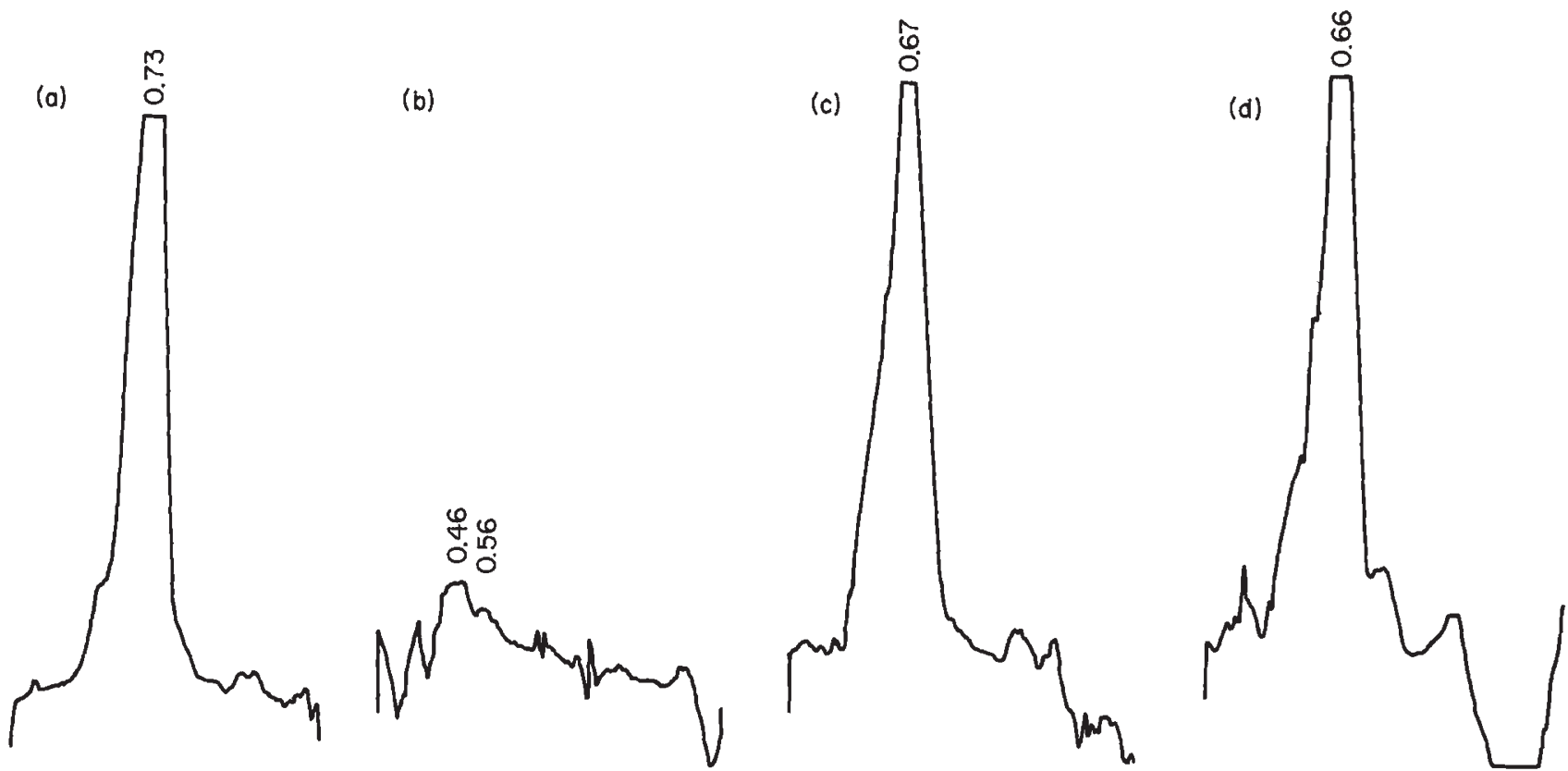

Fig. 1 Scanning graphs showing esterase bands made with IEF in (a) mare, (b) jack donkey, (c) male mule, (d) female hinny. 


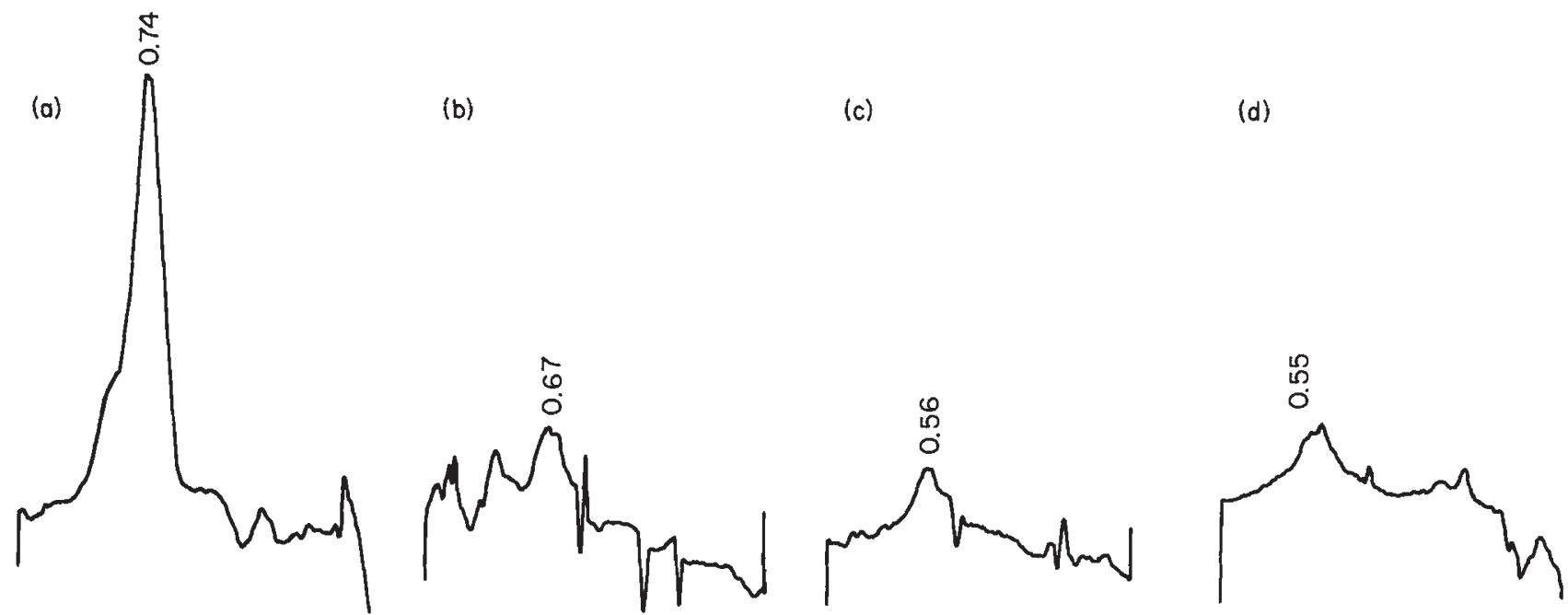

Fig. 3 Scanning graphs showing esterase bands in $(a) B_{1} \sigma^{*}(q$ mule $\times$ jack donkey $),(b) B_{1} \&\left(q\right.$ mule $\times$ jack donkey), $(c) B_{1} O^{\prime}(\&$ mule $\times$ jack donkey), (d) $B_{1} \&$ ( $\%$ mule $\times$ jack donkey).

Fig. 4 Scanning graphs showing esterase bands in (a) $B_{1} \%(\%$ hinny $\times$ jack donkey), (b) $B_{1}$ \& ( hinny $\times$ jack donkey), (c) $B_{1}$ o ( $\%$ hinny $\times$ jack donkey). (a)

(b)

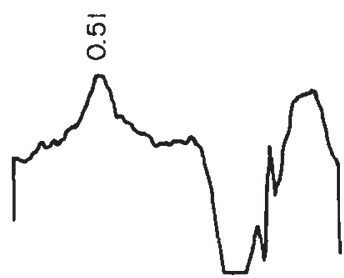

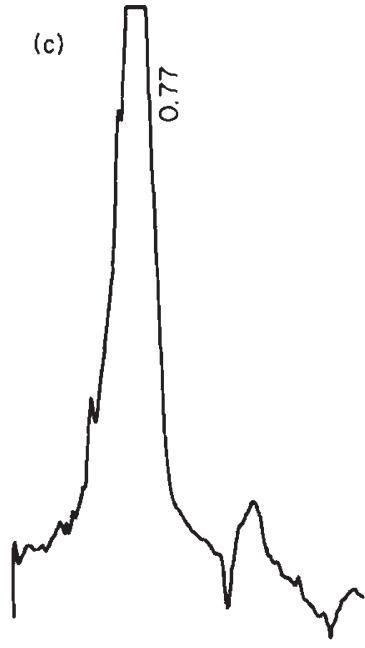

Two animals (Figs 3a and b) show a fast $E_{3}$ band (which can only have been transmitted by the mule), while the other two (Figs. $3 \mathrm{c}$ and d) lack such a band. Moreover, the $\mathrm{E}_{3}$ bands for the $\mathrm{B}_{1}$ hybrids in Fig. $3 \mathrm{a}$ and $b$ varied from each other, being much lighter in colour and showing a lower wave peak in the scanning graph for Fig. 3b than a.

Figure $4 a-c$ shows the results obtained for the three $B_{1}$ animals produced by crossing female hinnies and jack donkeys. The absence of an $E_{3}$ wave peak in Fig. $4 \mathrm{a}$ and $4 \mathrm{~b}$ contrasts with the pronounced peak seen in Fig. $4 c$, the fast band having been transmitted here by the horse component of the hinny. This result again clearly illustrates the variability of transmission of the horse gene for esterase isozyme from individual $F_{1}$ hybrids of the same bloodline to their $\mathrm{B}_{1}$ offspring.

\section{Discussion}

Our findings for esterase isozyme activity in horses, donkeys, mules and hinnies entirely support previous findings (e.g. Kaminski \& Gajos, 1964; Eldridge \& Susuki, 1976; Ryder et al., 1985), but for $\mathrm{B}_{1}$ hybrid offspring, previous data are unavailable. Our results open up a whole new area for discussion concerning the possible ways in which the horse chromosome carrying the esterase isozyme gene might be transmitted from a fertile mule or hinny to its backcross offspring. Among the three $\mathrm{B}_{1}$ progeny from female hinnies and jack donkeys, two have been shown to have no $E_{3}$ band in their sera, while in the third this band is present. Of the four $B_{1}$ offspring of female mules and jack donkeys, two show the presence of $E_{3}$ 
and two the absence. Overall, the results show that the horse esterase isozyme may or may not be transmitted to a $B_{1}$ animal, an irregular pattern of inheritance occurs from one mule or hinny to another. Karyotyping of all the eight $B_{1}$ animals used in the present study (Zong et al., 1985), together with independent data obtained for two other $B_{1}$ foals produced in China (Rong et al., 1988), has shown that the hybrid chromosome complements in all but one animal differ from that of either horse, donkey, mule or hinny. The chromosome findings are thus consistent with the irregular patterns of segregation found for the $E_{3}$ horse band of esterase isozyme, detectable from one $B_{1}$ animal to another in the present study.

The results are of some significance because they show quite clearly that the pattern of inheritance of horse and donkey chromosomes from mules and hinnies to their $B_{1}$ offspring can be irregular and need not necessarily follow the precise rules laid down in recent hypotheses. For example, to explain the occasional fertility of a mule, Anderson (1939) originally suggested that only maternal chromosomes might segregate into the ovum, a full balanced horse set thus being recovered. This theme was more recently expanded by Chandley (1981) who suggested that chromosome segregation in mules and hinnies might be governed according to the principles of 'affinity', a phenomenon that gives complete or near-complete separation of whole parental genomes at meiosis in hybrids. Our present results, however, support the idea that a mixture of horse and donkey chromosomes can pass into the ovum of a mule or hinny. The ratio and mixture perhaps varying from one $B_{1}$ animal to another.

The findings are of importance, not only because they may contribute to a fuller understanding of speciation, evolutionary biology and cell biology, but because they might also help us to understand why a gradual progression exists in mules and hinnies between those that show sterility and those that show partial or complete fertility (Zong \& Fan, 1989).

\section{References}

ANDERson, w. s. (1939) Fertile mare mules. J. Hered., 30, 549-551.

CHANDLEY, A. C. (1981) Does 'affinity' hold the key to fertility in the female mule? Genet. Res. Camb., 37, 105-109.

ELDRIDGE, F. AND SUZUKI, Y. (1976) A mare mule-dam or foster mother? J. Hered., 67, 353-360.

HU, N. AND WAN, X. (1985) The Application of Isozyme Techniques. Human Science and Technology Press, Beijing, pp. 158-161.

KAMINSKI, M. AND GAJOS, E. (1964) Comparative examination of carboxylic esterases in sera of horse, donkey and their hybrids. Nature, 201, 716-718.

RONG, R., CHANDLEY, A. C., SONG, J., MCBEATH, S., TAN, P. P., BAI, Q. AND SPEED, R. M. (1988) A fertile mule and hinny in China. Cytogenet. Cell. Genet., 47, 134-139.

RYDER, O. A., CHEMNICK, L. G., BOWLING, A. T. AND BENIRSCHKE, K. (1985) Male mule foal qualifies as the offspring of a female mule and jack donkey. J. Hered., 76, 379-381.

ZHENG, L. (1987) The Principles and Methods for Classification of Animals. Higher Education Press, Beijing, pp. 73-79.

ZONG, E. AND FAN, G. (1989) The variety of sterility and gradual progression to fertility in hybrids of the horse and donkey. Heredity, 62, 393-406.

ZONG, E., FAN, G., YIN, H., WANG, B., ZANG, C., SUN, M. AND JIAO, S. (1985) A study of chromosomes in hybrids $B_{1}$ 's between horses and donkeys. China Agric. Sci., 1, 83-85. 